\title{
SLAC MODULATOR AVAILABILITY AND IMPACT ON SLC OPERATION*
}

A. R. Donaldson and J. R. Ashton

Stanford Linear Accelerator Center, Stanford University, Stanford, CA 94309 USA

In 1991, the Stanford Linear Collider (SLC) operated, with diverse accelerator systems, at $60 \%$ availability. In the more auspicious 1992 and 1993 runs availability improved to over $80 \%$. For the $94 / 95$ run, the availability was also about $80 \%$. Ignoring the eclectic-accelerator, this discussion will assess the dependence of the SLC on the reliability and hence, availability, of 244 klystron modulator systems that provide power to the machine's bunched-particle beams. Klystron modulator availability must be $99 \%$ for the accelerator to function at the $75 \%$ level. Fortunately, an excess of modulator/klystrons provides some redundancy and, therefore, allows some freedom from the requirement that all 244 systems perform simultaneously. There are, however, 15 specific exceptions. They populate strategic positions at the injector, damping rings, and positron production area of the accelerator complex. These, systems-without-spares, directly influence overall accelerator availability. Their calculated availability as an ensemble is $90 \%$, but by chance they have operated at up to $99 \%$ [1]. Individually, a malfunction can bring an experimental program to a halt. The discussion includes a description of several improvements to increase future availability for the modulator system.

\begin{tabular}{|c|c|c|}
\hline TABLE I: Klystron/mo & Depl &  \\
\hline LOCATION & QUANITY & $\mathrm{E}[\mathrm{GeV}]^{1}$ \\
\hline Injector Stations & 5 & 0.2 \\
\hline Sector 1 Stations & 5 & 1.15 \\
\hline N \& S Damping Rings: & & 1.15 \\
\hline NRTL Compressor ${ }^{2}$ & $\mathbf{1}$ & \\
\hline SLTR Compressor ${ }^{2}$ & $\mathbf{1}$ & \\
\hline SRTL Compressor ${ }^{2}$ & $\mathbf{1}$ & \\
\hline Sectors 2 to 18 Stations & 135 & 32.8 \\
\hline Sector 19 Stations & 7 & 34.5 \\
\hline Positron Source: & & \\
\hline $\mathrm{e}^{-}$To Target Station ${ }^{2}$ & 1 & $30.5-31.5$ \\
\hline$e^{+}$Accelerate Station ${ }^{2}$ & $\mathbf{1}$ & 0.2 \\
\hline Sector 20 Stations & 7 & 36 \\
\hline Sectors 21 to 30 Stations & 80 & 55 \\
\hline Energy to SLC Arcs & & 47 \\
\hline Energy to Detector & & 46 \\
\hline Total Station Count & 244 & \\
\hline $\begin{array}{l}1 \text { Indicates the maximum } \\
\text { and does not include losse } \\
15 \text { degree offset for } B \\
\text { overhead for energy } \mathrm{f} \\
\text { modulators down for } \\
\text { klystrons down for maint }\end{array}$ & $\begin{array}{l}\text { sible energy } \\
\text { te to: } \\
\text { Damping } \\
\text { back } \\
\text { ntenance } \\
\text { nce. }\end{array}$ & se ali \\
\hline $\begin{array}{l}2 \text { Indicates stations whic } \\
\text { energy gain. }\end{array}$ & pre & \\
\hline
\end{tabular}

"Work supported by the Departiment of Energy contract DE-AC03-76SF00515

\section{MODULATOR/KLYSTRONDEPLOYMENT}

The linear accelerator presently uses 244 modulator/kdystron stations (in 1991 only 243 stations were used). From Table I it is almost apparent that SLC has more modulators than needed for the required detector energy. This allows modulators to be repaired by substituting operational but off beam modulators to avoid long repair times. At any given time there may be as many as 14 modulators available as spares. However this is not a universal situation, and there are 15 critical modulators (indicated in bold type) which do not have substitutes, hence their critical designation.

Table II offers the specifications for the klystronmodulator station. The modulator operates at high voltage and high current, conditions that essentially stress electronic components.

TABLE II: Klystron and Modulator Characteristics.

\begin{tabular}{rcl} 
Klystron Peak Power Out & 67 & $\mathrm{MW}$ \\
RF Pulse Width & 3.5 & $\mu \mathrm{S}$ \\
Klystron Beam Voltage & 350 & $\mathrm{kV}$ \\
Klystron Beam Current & 414 & $\mathrm{~A}$ \\
Modulator Peak Power Out & 150 & $\mathrm{MW}$ \\
Repetition Rate & 120 & $\mathrm{~Hz}$ (max) \\
Thyratron Anode Voltage & 46.7 & $\mathrm{kV}$ \\
Thyratron Anode Current & 6225 & $\mathrm{~A}$ \\
Pulse Transformer Ratio & $1: 15$ & \\
Voltage Pulse Width & 5.0 & $\mu \mathrm{s}$ (ESW) \\
Pulse Flattop Ripple & \pm 0.25 & $\%$ \\
Nominal PFN Impedance & 4 & $\Omega$ \\
Total PFN Capacitance & 0.70 & $\mu \mathrm{F}$ \\
\hline
\end{tabular}

\section{MODULATOR RELIABILITY}

The SLC must operate at $120 \mathrm{~Hz}$ with a very high degree of reliability and on a continuous basis. Fortunately, we have a modest excess of modulatorklystron systems which allows some measure of redundancy, and hence some freedom from the constraint that all 244 modulator/klystrons operate simultaneously.

The modulator log books for 1991 through 1995 were poured into a database in order to analyze the reliability and hence availability of the modulators. The log books also recorded station problems associated with the modulator computer interface, klystron (which included $\mathrm{rf}$, water, and vacuum problems), accelerator structure and waveguide problems allied with vacuum and water interlocks, klystron de magnet circuit, and 600 Vac variable voltage substation operation. The database was designed to 
reveal specific modulator problems and the frequency of those problems. Prior to this analysis these revelations existed as only anecdotal recollections among the modulator cognoscenti, the data had not been quantified, accordingly it couldn't be used to provide evidence for improving the reliability of the modulators.

For five years of analysis, we take two approaches. First we compare hours of SLC operation and modulator problem counts to calculate and plot mean time to failure (MTTF) for the various modulator components as part of an entire system. Second, we take all of the reliability data, combine it, calculate availability, and offer the results in Table III with a run by run summary in Table $\mathrm{TV}$.

The plots are divided into three types, the "reset \& adjustment" intervention, the "repair then run" occurrence, and finally the component failure situation that requires removal and replacement of a component or sub-system. Consider Figure 1, it shows the "reset \& adjustment" MTTF chart for the modulator system. The $x$-axis displays the category of reset or adjustment and the SLC operating year 1991, 92, 93, and 94/5. The MTTF in hours is on the $y$-axis. These hours indicate how often the reset or adjustments occur, or require a technician to travel to the Linac gallery. These MTTF's are not based on single modulators, but for the entire 244 station Linac. The modulators operated at $60 \mathrm{~Hz}$ for 1991 SLC run. The other three runs were at $120 \mathrm{~Hz}$ except for a few weeks of $60 \mathrm{~Hz}$ operation in $94 / 5$.

For the "Reset Main CB" category, the MTTF axis indicates how often intervention was required to reset this main modulator circuit breaker over four distinct periods of SLC operation. This circuit breaker can trip for several reasons, but the typical case involves thyratron latch up because of high reservoir voltage or a malfunctioning thyratron. Normally the circuit breaker trips because the over current fault circuit fails to open the primary contactor for the hv power supply. The plot indicates that some improvement in this category has occurred over the years. The installation of a ferro-resonant voltage regulator in 1993 may be responsible for this slight increase in MTTF for the $94 / 5 \mathrm{run}$. Until the contactor or control scheme are improved or replaced we will continue to be plagued by these nuisance trips.

\section{RELIABILITY AND AVAILABILITY}

The five year database contains 7,537 nonscheduled interventions with 3,167 hours of allied repaired time for the 21,840 hour SLC/modulator operating period. This operating period can not be accurately measured as the front end (the first 13 modulators) must always come on weeks before the rest of the modulators down the linac.
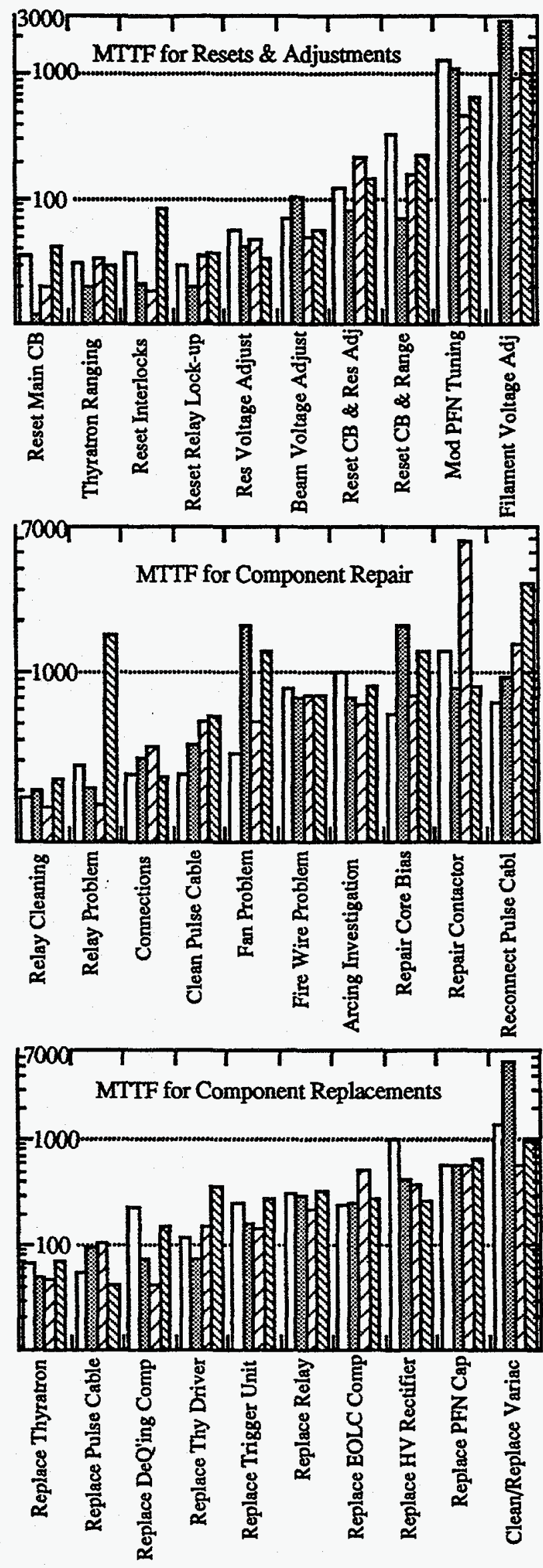

Figure 1. MTTF plots for the 244 modulator system. 


\section{DISCLAIMER}

This report was prepared as an account of work sponsored by an agency of the United States Government. Neither the United States Government nor any agency thereof, nor any of their employees, makes any warranty, express or implied, or assumes any legal liability or responsibility for the accuracy, completeness, or usefulness of any information, apparatus, product, or process disclosed, or represents that its use would not infringe privately owned rights. Reference herein to any specific commercial product, process, or service by trade name, trademark, manufacturer, or otherwise does not necessarily constitute or imply its endorsement, recommendation, or favoring by the United States Government or any agencv thereof. The views and opinions of authors expressed herein do not necessarily state or reflect those of the United States Government or any agency thereof. 


\section{DISCLAIMER}

Portions of this document may be illegible in electronic image products. Images are produced from the best available original document. 
The 21,840 hour figure was determined by approximate SLC operating periods for 1991 through 1995 which does not necessarily include front end turn on time or scheduled maintenance periods of less than 24 hours.

Total modulator-hours are then 244 (243 in 1991) modulators times 21,840 hours for 5.33 Mega modulatorhours of operation.

Assuming that a constant failure rate occurs for nonscheduled problems based on the operating hours and a typical Poisson distribution for electronic equipment failure,

Modulator System Failure Rate $=7537 / 21840 \mathrm{hr}$

Modulator System Failure Rate $=0.35$ problems/hour, or a problem occurs about once every three hours for the 244 units configured as a "system." This forces the modulator technicians to enter the linac gallery almost every three hours to correct a modulator problem. And these calculations don't include the external problems, e.g., vacuum and water interlocks for the klystron and accelerator waveguide, interface electronics or the $600 \mathrm{~V}$ ac utility power.

The modulator "mean time to failure" is then,

Modulator MTTF $=5.33 \mathrm{M} \mathrm{hr} . / 7537$

Modulator MTTF $=707$ hours,

which when considering the age of modulators, thyratron fault rate, and relay control circuitry seems appropriate (the database error could be as high as $\pm 5 \%$ ).

The calculation for the "mean time to repair" with our data gives,

Modulator MTTR $=3167 \mathrm{hr} . / 7537$

Modulator MTTR $=0.424 \mathrm{hr}$. $/ \mathrm{problem}$

or the average modulator problem (a repair or intervention) requires about 25 minutes to correct.

The final calculation of interest to the accelerator operator and physicist is modulator availability, or when can it be depended on to work. The reliability experts give several definitions for availability, we will use the following as it has been applied to other accelerator systems.

Modulator System Availability = 1- (Failure Rate)(MTTR) Modulator System Availability $=0.854$

This would be the "availability" if there were no spares for the modulators, however as mentioned earlier there are up to 14 spares available and they can be activated within 12 minutes to replace a faulty unit. Using the 12 minute or 0.2 hour repair/replacement as the MTTR, then increases the "availability" to 0.931 , a respectable increase that verifies the advantages of redundancy and available spares.

SLC operation is compromised when we run out of modulator spares, or when one of the 15 critical moduiators fails. The database contained 437 nonscheduled interventions for the 15 critical modulators with a total time for repair of 203 hours. We apply the above calculations for the critical modulators and then compare the data with the entire ensemble of 244 modulators in Table III.

TABLE III: System and Modulator Data for Four Runs.

\begin{tabular}{rrrl} 
& 244 System & 15 Critical \\
SLC Operating Period & 21,840 & $21,840 \mathrm{Hr}$ \\
SLC/Modulator-hours & $5.33 \mathrm{e6}$ & $3.27 \mathrm{e}$ & \\
No. of Interventions & 7537 & 437 & \\
Total Repair Time & 3167 & $203 \mathrm{Hr}$ \\
System Failure Rate & 0.345 & $0.020 \mathrm{P} / \mathrm{hr}$ \\
System MTTF & 2.9 & $50.0 \mathrm{Hr}$ \\
Modulator MTTF & 707 & $750 \mathrm{Hr}$ \\
Modulator MTTR & 0.424 & $.464 \mathrm{Hr}$ \\
System "Availability" & 0.855 & 0.991 & \\
System "A" w/ Spares & 0.931 & not applicable \\
\hline
\end{tabular}

The critical modulator value of 0.990 indicates that their availability was better than either of the above two calculations for Modulator System Availability which offered 0.854 for the no spares case, and 0.931 for the spares case, but it forebodes that the expected availability would be no better than 0.854 since there are no spares for the 15 critical modulators. We are lucky, or we give these modulators more attention when permitted by the schedule.

Finally, we arrive at the comparison of Availability for SLC and the modulator system. Table IV offers this data.

TABLE IV: Availability of SLC and Modulator Systems.

\begin{tabular}{rcccc} 
SLC Run Period & 1991 & 1992 & 1993 & $94 / 5$ \\
PRR (Hz) & 60 & 120 & 120 & 120 \\
Operating Hours & 4008 & 5568 & 5736 & 6528 \\
SLC Availability & 0.6 & 0.818 & 0.828 & 0.794 \\
System Mod "A" & 0.884 & 0.829 & 0.849 & 0.863 \\
Critical Mod "A" & 0.990 & 0.994 & 0.992 & 0.991 \\
\hline
\end{tabular}

\section{CONCLUSIONS}

SLC availability increased while the 15 Critical Modulator Availability wavered about 0.99 indicating that the modulator system does not seriously impact SLC performance. We continue to improve the reliability of the system. Presently we are installing a device, an "anode reactor" that extends the life of the pulse cable. It has definitely improved cable lifetimes in six modulators where it has been installed. But even if cable lifetimes improve by a factor of three "Availability" only increases by $0.9 \%$.

\section{REFERENCES}

[1] A.R. Donaldson and J.R. Ashton, "SLAC Modulator Operation and Reliability in the SLC Era," 1992 20th Power Modulator Symposium, IEEE Conference Record CH3180-7/92/0000-152. 